\title{
ARTICLE OPEN \\ Periodontitis induced by bacterial infection exacerbates features of Alzheimer's disease in transgenic mice
}

Naoyuki Ishida ${ }^{1,2,3}$, Yuichi Ishihara ${ }^{1}$, Kazuto Ishida ${ }^{4}$, Hiroyuki Tada ${ }^{3}$, Yoshiko Funaki-Kato ${ }^{1,2,3}$, Makoto Hagiwara ${ }^{3}$, Taslima Ferdous ${ }^{5}$, Mohammad Abdullah ${ }^{5}$, Akio Mitani ${ }^{2}$, Makoto Michikawa ${ }^{5}$ and Kenji Matsushita ${ }^{3}$

Periodontitis is a localized infectious disease caused by periodontopathic bacteria, such as Porphyromonas gingivalis. Recently, it has been suggested that bacterial infections may contribute to the onset and the progression of Alzheimer's disease (AD). However, we do not have any evidence about a causative relationship between periodontitis and AD. In this study, we investigated by using a transgenic mouse model of $A D$ whether periodontitis evoked by $P$. gingivalis modulates the pathological features of $A D$. Cognitive function was significantly impaired in periodontitis-induced APP-Tg mice, compared to that in control APP-Tg mice. Levels of Amiloid $\beta(A \beta)$ deposition, $A \beta 40$, and $A \beta 42$ in both the hippocampus and cortex were higher in inoculated APP-Tg mice than in control APP-Tg mice. Furthermore, levels of IL-1 $\beta$ and TNF- $\alpha$ in the brain were higher in inoculated mice than in control mice. The levels of LPS were increased in the serum and brain of $P$. gingivalis-inoculated mice. $P$. gingivalis LPS-induced production of A $\beta 40$ and $A \beta 42$ in neural cell cultures and strongly enhanced TNF- $\alpha$ and IL-1 $\beta$ production in a culture of microglial cells primed with $A \beta$. Periodontitis evoked by $P$. gingivalis may exacerbate brain $A \beta$ deposition, leading to enhanced cognitive impairments, by a mechanism that involves triggering brain inflammation.

npj Aging and Mechanisms of Disease (2017)3:15; doi:10.1038/s41514-017-0015-x

\section{INTRODUCTION}

Periodontitis is a chronic inflammatory disorder in the oral cavity that causes destruction of supportive tissues including the alveolar bone around teeth, finally leading to tooth loss. A resident biofilm, so-called dental plaque, that forms in subgingival pockets evokes chronic inflammation in periodontal tissues and causes alveolar bone loss. ${ }^{1}$ Periodontitis develops due to the interaction between periodontal pathogenic bacteria and the host. One of the important periodontal pathogens, Porphyromonas gingivalis, is strongly involved in the onset and progression of periodontitis. $P$. gingivalis and its toxins, such as lipopolysaccharide (LPS) induce the production of proinflammatory cytokines and chemokines and promote inflammation in periodontal tissues. Studies have shown possible links between periodontitis and diseases including diabetes, ${ }^{2,3}$ atherosclerosis, ${ }^{4,5}$ osteoporosis, ${ }^{6}$ coronary heart disease, ${ }^{7,8}$ and Alzheimer's disease (AD). ${ }^{9-13}$ Results of studies have shown intravascular infiltration of periodontitis-related bacteria and their spread to target organs, but the mechanisms by which the bacteria cause diseases are not fully understood.

$A D$ is a brain disorder that affects a region of the brain that controls cognitive function and memory. In the initial stage of this disease, recent memory is affected, but long-term memory, learning, decision and communication capabilities are also gradually affected as the disease progresses. ${ }^{14,15}$ Lines of evidence have suggested that $A D$ is caused by accumulation of amyloid $\beta$ peptide $(A \beta)$, leading to tauopathy accompanied by synaptic dysfunction and intracerebral inflammation, which is assumed to be caused by $A \beta$ deposits. ${ }^{16-18}$ Although it has been reported that long-term administration of nonsteroidal anti-inflammatory drugs can prevent the occurrence of neurodegenerative diseases, ${ }^{19}$ it has been claimed in some reports that there is no such effect. ${ }^{20}$ In the immune response in the central nervous system, microglia play a central role. ${ }^{21}$ Microglia function in the elimination of waste products that have accumulated in the brain. These cells also produce cytokines, such as interleukin (IL)- $1 \beta, \mathrm{IL}-6$, and tumor necrosis factor- $a$ (TNF- $\alpha$ ), and reactive oxygen species, and they induce neurodegeneration in $A D$, indicating the possibility that they promote. ${ }^{21,22}$

It is possible that chronic inflammation that has developed in peripheral organs exacerbates the pathology of $A D$, and one of such chronic inflammatory diseases is periodontitis. Periodontal pathogenic bacteria spread throughout the body via blood vessels and airways. In addition, it is believed that inflammatory mediators, such as cytokines produced in periodontal tissues are carried to target organs in a hematogenous manner, exacerbating the inflammatory response in the organs. ${ }^{23}$ nterestingly, $P$. gingivalis is frequently detected in autopsied brain tissue of $A D$ patients. ${ }^{24}$ These findings suggest that periodontal pathogenic bacteria may exacerbate the pathology of AD. In addition, several studies have shown correlations of periodontal diseases with cognitive function and AD..$^{9-13}$ However, the molecular mechanism by which periodontitis is involved in $A D$ pathogenesis has not been clarified.

\footnotetext{
${ }^{1}$ Department of Operative Dentistry, Endodontology and periodontology, School of Dentistry, Matsumoto Dental University, 1780 Hirookaobara, Shiojiri, Nagano 399-0781, Japan; ${ }^{2}$ Department of Periodontology, School of Dentistry, Aichi Gakuin University, 2-11 Suemori-dori, Chikusa-ku, Nagoya 464-8651, Japan; ${ }^{3}$ Department of Oral Disease Research, National Center for Geriatrics and Gerontology, 7-430 Morioka-cho, Obu 474-8511, Japan; ${ }^{4}$ Department of Physical Therapy, Graduate School of Medicine, Nagoya University, 1-1-

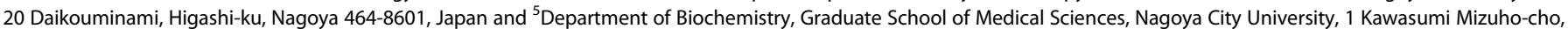
Mizuho-ku, Nagoya 467-8601, Japan

Correspondence: Makoto Michikawa (michi@med.nagoya-cu.ac.jp) or Kenji Matsushita (kmatsu30@ncgg.go.jp)
}

Received: 21 July 2016 Revised: 4 September 2017 Accepted: 17 October 2017

Published online: 06 November 2017 
In this study, we induced experimental periodontitis by $P$. gingivalis infection in the oral cavity of amyloid precursor protein (APP) transgenic mice and examined the effect of periodontitis on pathophysiology of $A D$ in those mice.

\section{RESULTS}

Development of periodontitis by $P$. gingivalis infection in APP-Tg mice

To develop experimental periodontitis in APP-Tg mice, we inoculated the mice with $P$. ginigivalis ATCC 33,277 mixed with carboxymethyl cellulose, which was delivered orally. After 5 weeks, we evaluated alveolar bone loss in the mice. As shown in Fig. 1, P. gingivalis-infected mice displayed significantly increased alveolar bone loss compared with that in control mice, as indicated by a decrease in relative amounts of bone around mandibular molars of infected mice. Alveolar bone resorption in the mesial side and furcation area of the $\mu \mathrm{m}^{2}$, the level of $A \beta$ deposition was increased in the hippocampus of $P$. gingivalis-infected mice $(19,182.2 \pm$ $\left.7334.9 \mu \mathrm{m}^{2}\right)(P=0.0028, F=0.82)$. The $A \beta$ deposition area in the cortex in the $P$. gingivalis-infected group $\left(4263.8 \pm 3257.2 \mu \mathrm{m}^{2}\right)$ was larger than that in the control group $\left(2658.2 \pm 1312.6 \mu \mathrm{m}^{2}\right)$ but these values were not significantly different $(P=0.23, F=$ 0.041) (Fig. 2).

We next examined the concentrations of $A \beta$ in the brains from $P$. gingivalis-infected APP-Tg mice. As shown in Fig. $3 c$, the brain levels of $A \beta 40$ and $A \beta 42$ in $P$. gingivalis-inoculated mice than in control mice. Production levels of $A \beta 40$ and $A \beta 42$ in the hippocampus in the control group were $24.8 \pm 8.5$, and $209.8 \pm$ $77.1 \mathrm{ng} / \mathrm{\mu g}$ protein, respectively. On the other hand, those levels in the hippocampus in the $P$. gingivalis-infected group were $35.4 \pm$ 13.1 and $307.1 \pm 99.7 \mathrm{ng} / \mathrm{\mu g}$ protein, respectively. The values were significantly different ( $A \beta 40: P=0.047, F=0.21 ; A \beta 42: P=0.025, F$ $=0.45$ ) between the groups. $A \beta 40$ and 42 production levels in the cortex in the control group were $6.16 \pm 2.3$ and $52.5 \pm 27.6 \mathrm{ng} / \mathrm{\mu g}$ protein, respectively, and the levels in the cortex in the $P$. gingivalis-infected group were $11.4 \pm 5.7$ and $84.3 \pm 33.1 \mathrm{ng} / \mathrm{\mu g}$ protein, respectively. The values were also significantly different (Aß40: $P=0.011, F=0.01$; $A \beta 42: P=0.031, F=0.62$ ) between the groups.

$A D$ is caused by accumulation of $A \beta$ due to intracerebral inflammation, and increased levels of proinflammatory cytokines, such as TNF- $\alpha$ and IL-1 $\beta$ were shown in AD patients. Therefore, we examined whether $P$. gingivalis infection affects the levels of TNF- $\alpha$ and IL-1 $\beta$ in the brains of APP-Tg mice. Quantification using ELISA
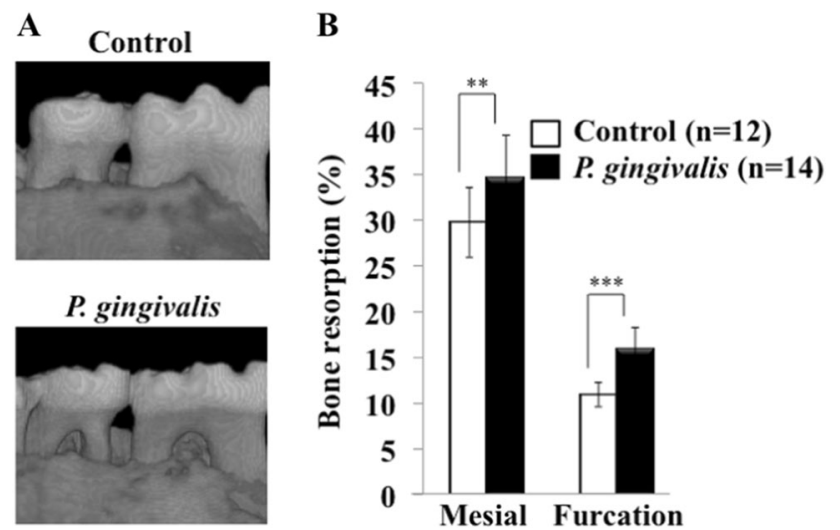

Fig. 1 Evaluation of alveolar bone loss in P. gingivalis-infected APPTg mice. a Alveolar bone resorption (imaged by $\mu$-CT). Control: Mice inoculated with CMC alone, P. gingivalis: Mice inoculated with CMC and $P$. gingivalis. b Alveolar bone resorption was evaluated in the furcation and mesial side of the second molar mandible. Results are expressed as means \pm S.D., ${ }^{* *} p<0.01,{ }^{* * *} p<0.001$

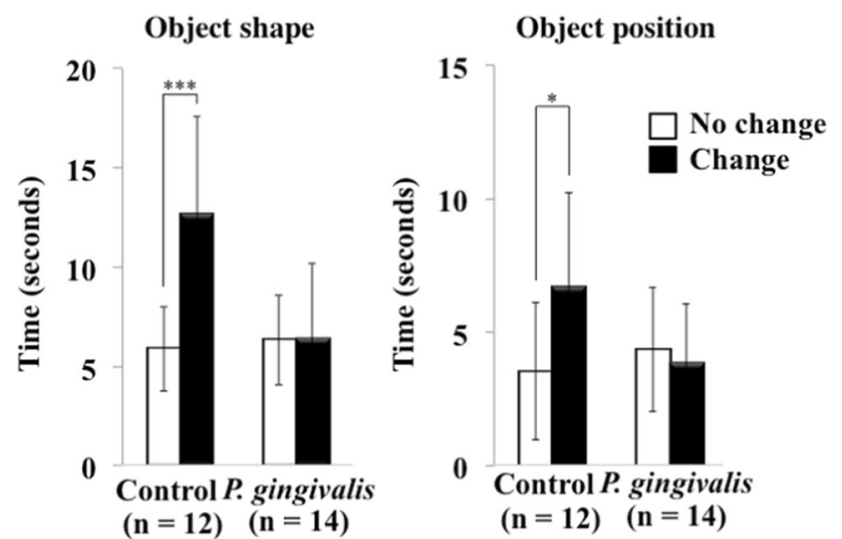

Fig. 2 Evaluation of cognitive function in $P$. gingivalis-infected APP$\mathrm{Tg}$ mice. Results are expressed as means \pm S.D., ${ }^{*} p<0.05$, ${ }^{* * *} p<$ 0.001

showed that the brain levels of IL-1 $\beta$ and TNF- $\alpha$ were higher in the $P$. gingivalis-inoculated mice than in the control mice (IL-1 $\beta$ : $17.5 \pm$ $2.3 \mu \mathrm{g} / \mathrm{ml}$ vs. $14.4 \pm 2.6 \mu \mathrm{g} / \mathrm{ml}, P=0.0062, F=0.66$; TNF-a: $60.2 \pm$ $2.8 \mu \mathrm{g} / \mathrm{ml}$ vs. $57.3 \pm 2.2 \mu \mathrm{g} / \mathrm{ml}, P=0.016, F=0.51$ ) (Fig. $3 \mathrm{~d}$ ).

Endotoxin concentrations in the brain and serum of $P$. gingivalisinfected APP-Tg mice

We then examined the mechanism by which $P$. gingivalis infection enhanced brain inflammation. A recent study showed that $P$. gingivalis and its LPS were found at a high frequency in autopsied brain tissues of patients who died of AD; however, they were not found in normal human brain tissues. Therefore, we measured the concentrations of bacterial LPS in the sera and brains of $P$. gingivalis-inoculated APP-Tg mice. As shown in Fig. 4, although endotoxin was detected even in the sera and brains of control mice $(3.51 \pm 0.74 \mathrm{EU} / \mathrm{ml}$ and $0.05 \pm 0.03 \mathrm{EU} / \mathrm{ml}$, respectively), the levels were increased in the sera and brains of $P$. gingivalisinoculated mice $(4.54 \pm 0.88 \mathrm{EU} / \mathrm{ml}$ and $0.12 \pm 0.06 \mathrm{EU} / \mathrm{ml}$, respectively) and the values were different (Sera: $P=0.033, F=0.74$; Brains: $P=0.022, F=0.2$ ).

Induction of $A \beta$ by stimulation with $P$. gingivalis LPS in neuronal cell cultures

To try to examine the mechanism by which $P$. gingivalis LPS enhances brain inflammation, we examined whether $P$. gingivalis LPS induces $A \beta$ production in murine neuronal cell cultures. As shown in Fig. 5, $A \beta 40$ and $A \beta 42$ production levels were increased in the media in neuronal cell cultures stimulated with $1.0(105.9 \pm$ $3.4 \mathrm{pmol} / \mathrm{L}$ vs. $151.9 \pm 3.4 \mathrm{pmol} / \mathrm{L} ; P=0.002, F=0.084)$ and $10.0 \mu \mathrm{g} / \mathrm{ml}$ $(105.9 \pm 3.4 \mathrm{pmol} / \mathrm{L}$ vs. $152.3 \pm 5.0 \mathrm{pmol} / \mathrm{L} ; P=0.00052, F=0.65)$ of $P$. gingivalis LPS.

Effect of $P$. gingivalis LPS on A $\beta$-induced cytokine production in microglia cell cultures

$A \beta$ oligomers induce overproduction of proinflammatory cytokines, such as TNF- $\alpha$ and IL-1 $\beta$. To determine the effects of $P$. gingivalis LPS on A 342 -induced inflammatory responses in microglia, various concentrations of $P$. gingivalis LPS were added to microglial cell cultures primed with fibrillized $A \beta 42$, and protein levels of TNF- $\alpha$ and IL-1 $\beta$ in the media were measured by ELISA. Small amounts of TNF- $\alpha$ were induced in the media from microglial cells primed by $10 \mu \mathrm{M} \mathrm{A} \beta 42$ and by stimulation with $0.01-1.0 \mu \mathrm{g} / \mathrm{ml}$ P. gingivalis LPS. However, by stimulation with $0.1-1.0 \mu \mathrm{g} / \mathrm{ml} P$. gingivalis LPS, the production of TNF-a was significantly increased in the media from $A \beta$ 42-primed microglia (Aß42: $48.4 \pm 18.5 \mathrm{pg} / \mathrm{ml}$ vs. $A \beta 42+0.1 \mu \mathrm{g} / \mathrm{ml}$ LPS: $162.6 \pm 12.0 \mathrm{pg} / \mathrm{ml}$, 
A

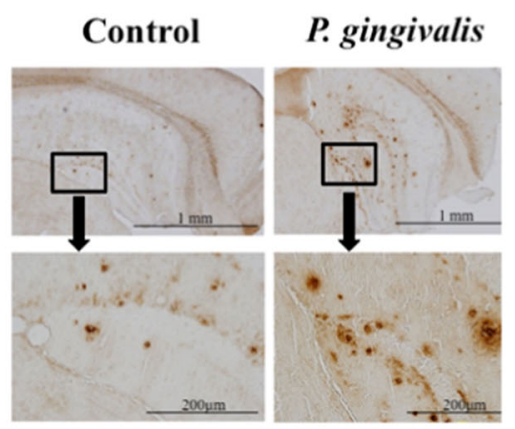

B Hippocampus

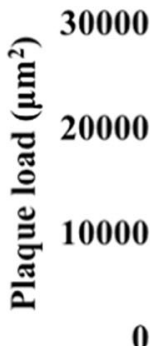

Cortex

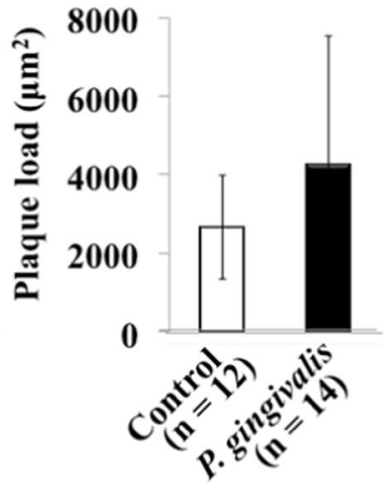

C
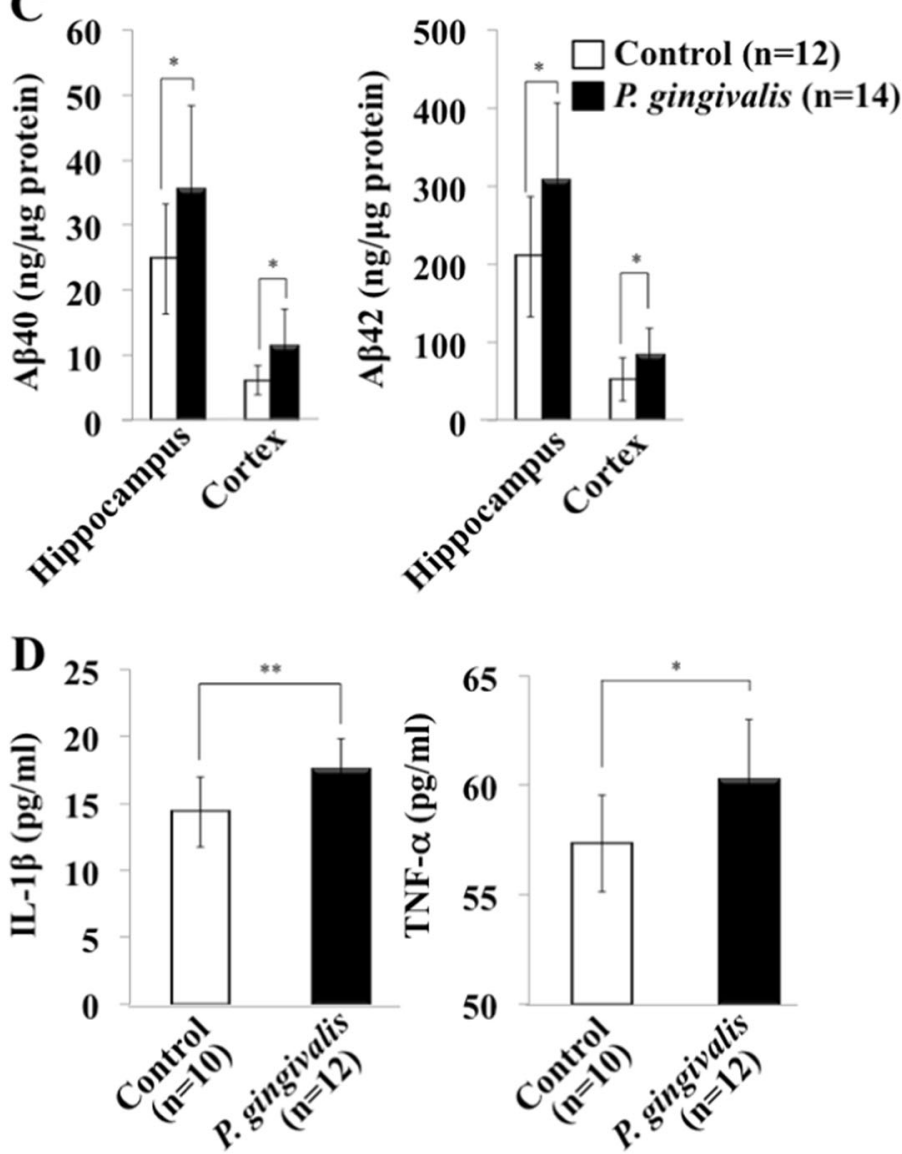

Fig. 3 Amyloid plaque deposition in the cortex and hippocampus of APP-Tg mice. a Immunostaining of $A \beta$ in brain sections. $\mathbf{b} A \beta$ loads in brain sections. Results are expressed as means \pm S.D., ${ }^{* *} p<0.01$. c A $\beta 40$ and A $\beta 42$ in the cortex and hippocampus of $P$. gingivalis-infected APPTg mice. Concentrations of $A \beta 40$ and $A \beta 42$ in the extracts of brain were measured by ELISA. Control: Mice inoculated with CMC alone, $P$. gingivalis: Mice inoculated with CMC and $P$. gingivalis. Results are expressed as means \pm S.D., ${ }^{*} p<0.05$. d TNF- $\alpha$ and IL- $1 \beta$ in the brain in $P$. gingivalis-infected APP-Tg mice. Amounts of TNF- $\alpha$ and IL-1 $\beta$ in brain extracts were measured by ELISA. Results are expressed as means \pm S.D., ${ }^{*} p<0.05,{ }^{* *} p<0.01$

$P=0.0038, F=0.51 ; A \beta 42: 48.4 \pm 18.5 \mathrm{pg} / \mathrm{ml}$ vs. $A \beta 42+1.0 \mu \mathrm{g} / \mathrm{ml}$ LPS: $355.7 \pm 10.9 \mathrm{pg} / \mathrm{ml}, \quad P=0.0012, F=0.54$ ) (Fig. 6). On the other hand, IL-1 $\beta$ production was not induced in the media in A 342 -primed microglial cell cultures. However, $1.0 \mu \mathrm{g} / \mathrm{ml}$ of LPS stimulation significantly enhanced $\mathrm{IL}-1 \beta$ production in $A \beta 42$ primed microglial cell cultures (LPS: $7.5 \pm 2.3 \mathrm{pg} / \mathrm{ml}$ vs. LPS $+A \beta 42$ : $59.5 \pm 12.3 \mathrm{pg} / \mathrm{ml}, P=0.037, F=0.28$ ). These results suggest that $P$. gingivalis LPS may exacerbate brain inflammation in AD by activating microglia cooperatively with $A \beta$.

\section{DISCUSSION}

Recent epidemiological evidence has shown that periodontitis and its causative bacteria may also be associated with $A D$. However, these causative relationships have not been shown. In the present study, we demonstrated for the first time that periodontitis, caused by $P$. gingivalis infection, exacerbates the pathological features of $A D$ in a murine model.

How does $P$. gingivalis infection exacerbate the pathological features of $A D$ ? Chronic inflammation in the brain is thought to 

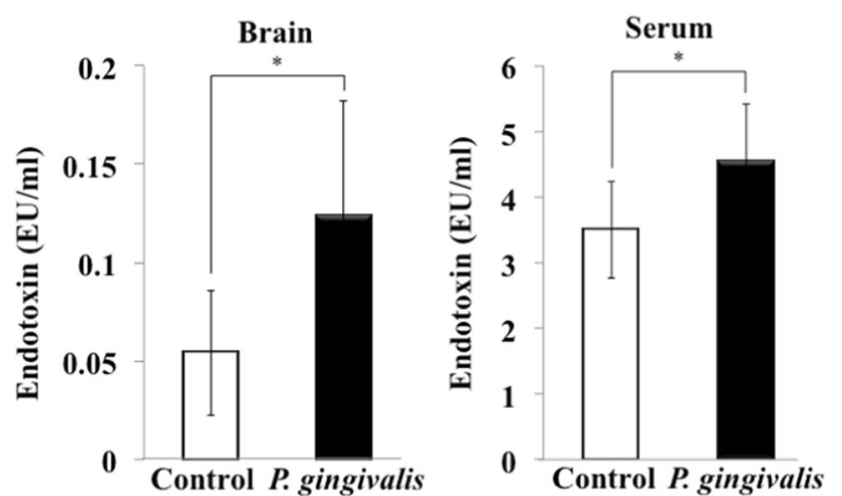

Fig. 4 Concentrations of endotoxin in the brain and serum from $P$. gingivalis-infected mice. Levels of endotoxin in the brain and serum were measured by Limulus assay. Results are expressed as means \pm S.D., ${ }^{*} p<0.05,{ }^{* *} p<0.01$
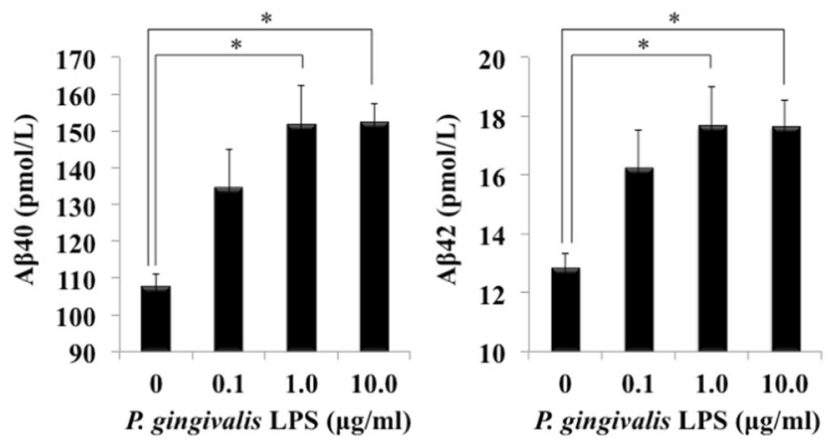

Fig. $5 \quad P$. gingivalis LPS induces $A \beta$ production in mouse neural cell cultures. Neural cells isolated from mouse brain were stimulated with $P$. gingivalis LPS for $24 \mathrm{~h}$. Amounts of $A \beta 40$ and $A \beta 42$ in the media were measured by ELISA $\left(n=3\right.$, mean \pm S.D., $\left.{ }^{*} p<0.05\right)$
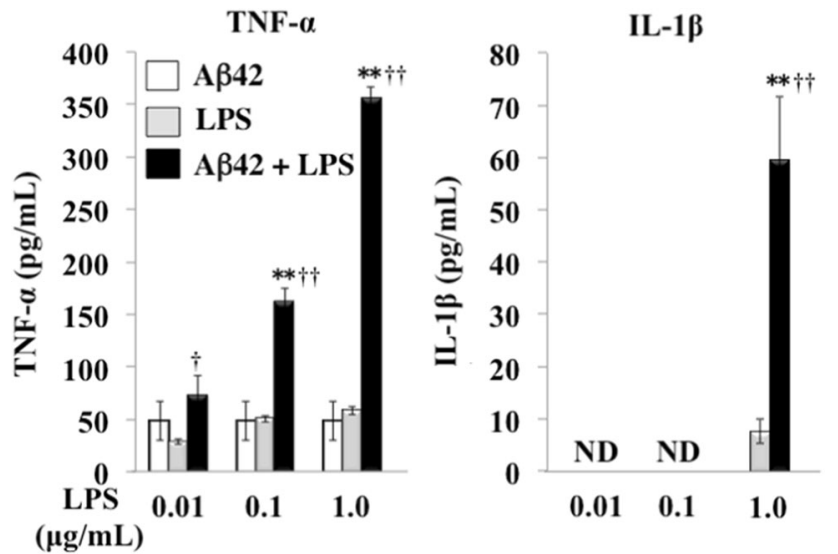

Fig. 6 P. gingivalis LPS enhances $A \beta$-induced cytokine production in microglia cell cultures. Microglial cells were stimulated with $10 \mu \mathrm{M}$ $\mathrm{A} \beta 42$ for $6 \mathrm{~h}$ and further stimulated with $P$. gingivalis LPS $(0.01,0.1$, $1.0 \mu \mathrm{g} / \mathrm{ml}$ ) for $24 \mathrm{~h}$. Amounts of TNF- $\alpha$ and IL- $1 \beta$ in the media were quantified by ELISA ( $n=3$, mean \pm S.D.). ${ }^{* *} p<0.01$ vs. A $\beta 42$ alone; ${ }^{\dagger} p<0.05,{ }^{+\dagger} p<0.01$, vs. LPS alone

play an important role in the etiology of $A D$ and it is featured by the production of proinflammatory cytokines, such as TNF- $\alpha, \mathrm{IL}-1 \beta$, and IL-6, by activated microglia. ${ }^{19,25}$ It was shown that $A \beta$ fibrils can induce excess production of cytokines and neurotoxic mediators to activate microglia and can injure neurons. ${ }^{26,27}$ On the other hand, previous studies demonstrated that chronic bacterial infections, such as rheumatoid arthritis, leprosy, tuberculosis, syphilis, and osteomyelitis are often associated with the deposition of amyloid. ${ }^{28}$ The bacterial endotoxin LPS is a major inducer of inflammation and LPS may induce chronic neuroinflammation, $A \beta$ accumulation/deposition, and impairment of cognitive function. ${ }^{29} \mathrm{~A}$ recent study showed that $P$. gingivalis LPS was found at a high frequency in autopsied brain tissues of patients who died of AD; however, it was not found in normal human brain tissues. ${ }^{24}$ It has also shown that $P$. gingivalis could enter the brain of ApoE knockout mice. ${ }^{30}$ For the mechanism of $P$. gingivalis entry into the brain, it has been shown that $P$. gingivalis has the ability to bind to E-selectin via its OmpA-like protein, ${ }^{31}$ and can invade cells by activation of intercellular adhesion molecule (ICAM)-1 and the small G-protein Rab5 in host cells. ${ }^{32,33}$ These lines of evidence suggest that $P$. gingivalis and its toxin probably spread by a hematogenous route and are transmitted into the brain via the blood-brain barrier (BBB). Besides the experiments using $\mathrm{J} 20$ mice, we also performed experiments to examine memory function, levels of serum cytokines and endotoxin, and endogenous brain A $\beta$ levels in $P$. gingivalis-infected WT mice. The results of the novel objection test showed that cognitive function was impaired in mice of the $P$. gingivalis administration group compared with that in the control mice (Supplementary Fig. 1), but the brain $A \beta$ level and serum TNF- $a$, and endotoxin levels were not different from those in the control group (Supplementary Figs. 2 and 3). A small amount of TNF-a was also found in the brain of WT mice, but there was no significant difference between the $P$. gingivalis administration group and control group (data not shown). In this experiment using WT mice, individual differences among mice were large, and we therefore could not clearly confirm that the enhancement of brain inflammation was due to $P$. gingivalis infection, but we could confirm this tendency. Therefore, we believe that brain inflammation may be involved in the mechanisms by which cognitive function declined in the $P$. gingivalis-administered WT mice. These results also suggest that infection with $P$. gingivalis in WT mice reduces cognitive function but does not elicit AD-specific pathologies, such as $A \beta$ increase. These findings suggest that $P$. gingivalis infection may be related to exacerbation of $A D$ pathology rather than affecting the onset of AD. In an in vitro BBB permeability test, it was revealed that LPS may penetrate the BBB (Supplementary Fig. 4). The results suggest that $\mathrm{J} 20$ mice are more susceptible than WT mice to $P$. gingivalis and that inflammation is strongly induced and reflected in the blood. Inflammatory mediators in the blood enhance BBB permeability and may penetrate into the brain. Actually, the increases in inflammatory cytokine levels in the brain in APP-Tg mice were greater than those in wild-type mice after peripheral LPS injection. ${ }^{34}$ In addition, the permeability of the BBB was increased in APP-Tg mice by the peripherally evoked inflammation. These inflammatory mediators may activate microglia and promote $A \beta$ production in cells. ${ }^{35}$ In addition, the activation of innate immunity with these factors in brain could affect $A D$ pathology. ${ }^{36}$ Therefore, the increased innate immune response in the brain originating from the intraoral infection of $P$. ginigvalis may have exacerbated $A D$ pathology. In the future, we will examine the detailed mechanism.

Periodontitis is a major cause of loss of teeth. Since there is a significant correlation between $A D$ and tooth loss, it has been suggested that periodontitis may be a risk factor for AD. ${ }^{37,38}$ Tooth loss reduces chewing function, thereby reducing cerebral blood flow, and then cognitive function may deteriorate. Oue et al. reported that cognitive decline was observed in the APP transgenic mouse from which teeth had been removed, but deposition of $A \beta$ and induction of brain inflammation were not observed. ${ }^{39}$ On the other hand, in this study, we found that APP transgenic mice that had been infected with $P$. gingivalis and had developed periodontal disease showed increased cerebral $A \beta$ deposition and enhanced intracerebral inflammatory response, as well as a decrease in cognitive function. These results suggest that 
cognitive decline due to periodontal disease and that due to tooth loss are caused by different molecular mechanisms. Namely, tooth loss causes memory impairment in an amyloid-independent manner and is associated with a decreased number of neural cells in the hippocampus by reduction of BDNF signaling. ${ }^{37}$ We also found that chewing dysfunction caused by liquid diet induces memory impairment and hippocampal neuronal loss due to impaired BDNF cascade. ${ }^{40}$

An intervention study to test the efficacy of periodontal treatment on $A D$ features are needed to conclude that periodontitis is truly a risk factor for AD; however, this study suggests a new possibility that periodontitis directly deteriorate the pathological features of $A D . A D$ is a serious problem in the world; however, there is still no effective method for the prevention of $A D$ or a fundamental method for treatment. ${ }^{41} A \beta$ deposition in the brain is initiated during the first half of the 40s, more than 15-20 years prior to the onset of cognitive impairment in $A D$ patients. ${ }^{42,43}$ It is the period in which patients with periodontal diseases also begin to increase drastically. Because, periodontal infections are treatable, treatment of periodontal diseases during this period may be effective for delaying the onset or progression of $A D$.

\section{METHODS}

Mice

Female hemizygous transgenic (hAPP-J20) and non-transgenic mice (WT) were obtained from the J20 line, which expresses hAPP containing both the Swedish and Indiana mutations under the control of a PDGF- $\beta$ chain promoter. ${ }^{44}$ Mice were housed in a pathogen-free facility at a maximum of five mice per cage until the study began, at which time the mice were housed individually. The mice were kept on a 12-h light/dark cycle (lights on at 7:00 am) and, food and water were available ad libitum. ${ }^{45}$ All mice were bred and maintained in specific pathogen-free conditions in the animal facility at Aichigakuin University, and all experiments were performed in accordance with institutional guidelines of the Animal Experiment Committee and Gene Recombination Experiment Committee.

Bacteria and culture conditions

Culture of $P$. gingivalis was performed according to previous reports. ${ }^{31,46}$ Briefly, P. gingivalis ATCC 33,277 was cultivated with $5 \%$ laked rabbit bloodsupplemented brucella HK agar (Kyokuto Pharmaceutical Industrial Co., Ltd., Tokyo, Japan) with hemin $(2.5 \mu \mathrm{g} / \mathrm{ml})$, menadione $(5 \mu \mathrm{g} / \mathrm{ml})$, and dithiothreitol $(0.1 \mathrm{mg} / \mathrm{ml})$ and in Trypticase soy broth $(B D$, Franklin Lakes, $\mathrm{NJ})$ with yeast extract $(2.5 \mathrm{mg} / \mathrm{ml})$, hemin $(2.5 \mu \mathrm{g} / \mathrm{ml})$, menadione $(5 \mu \mathrm{g} / \mathrm{ml})$, and dithiothreitol $(0.1 \mathrm{mg} / \mathrm{ml})$. Bacterial cells were collected, washed, and suspended in phosphate-buffered saline (PBS). The concentration of bacteria was determined with a spectrophotometer at an optical density of $660 \mathrm{~nm}$. Live $P$. gingivalis ( $10^{9} \mathrm{CFU}$ ) was resuspended in $100 \mu \mathrm{l}$ of PBS with $2.5 \%$ carboxymethylcellulose.

\section{Development of periodontitis in mice}

A mouse model of periodontitis was established as described previously with minor modification. ${ }^{46}$ Briefly, sulfamethoxazole $(700 \mu \mathrm{g} / \mathrm{ml})$ and trimethoprim $(400 \mu \mathrm{g} / \mathrm{ml})$ in water bottles were given to 62 -week-old J20 female mice at any time for 10 days. Three days after the treatment, $10^{9}$ CFU of live $P$. gingivalis in $100 \mu \mathrm{l}$ of PBS with $2.5 \%$ carboxymethylcellulose was applied to the gingival margin of each mouse under brief isoflurane anesthesia. After inoculation with P. gingivalis, the mice were fasted for $1 \mathrm{~h}$. PBS containing only $2.5 \%$ carboxymethyl cellulose $(100 \mu \mathrm{l})$ was administered to the control group. Five weeks after the oral challenge, a novel objection test was performed. The mice were then sacrificed, and the sera and brains were collected. Maxillary specimens were also collected for micro-CT and histopathological studies.

\section{Evaluation of mandibular bone loss}

To evaluate morphological changes in the alveolar bone, the mandibular alveolar bone was scanned by micro CT (R_mCT AX; Rigaku Corporation, Tokyo, Japan) in mice 11 weeks after inoculation of $P$. gingivalis. The computed tomography was set according to slice thickness $(50 \mu \mathrm{m})$, voltage $(90 \mathrm{kV})$, and electrical current $(150 \mu \mathrm{A})$. Three-dimensional images were made using TRI/3D Bone (Ratoc, Tokyo, Japan). The distance from the mesial buccal cement-enamel junction to the alveolar bone crest of the second molar was measured as a reference for bone height. The percentage of bone resorption was calculated as the distance from the mesial buccal cement-enamel junction to the alveolar bone crest divided by the length of the root $\times 100 .{ }^{47}$

\section{Evaluation of cognitive function}

The novel objection test was performed on mice to test cognitive memory as described previously. ${ }^{48}$ Briefly, in the training session, we placed two objects in a box $(30 \mathrm{~cm} \times 30 \mathrm{~cm} \times 35 \mathrm{~cm}$ high). The objects were a white lamp and a square bottle, the shapes and colors being different but sizes being almost the same. The mouse was then placed in the box and search behavior for the two objects was recorded for $10 \mathrm{~min}$. We defined a mouse searching for an object as a mouse facing an object, touching an object, or performing an action to sniff an object. After $24 \mathrm{~h}$ of the training session, one of the objects used during the training was replaced with a new object, and the mice were returned to the box. The mice were allowed to freely search for $3 \mathrm{~min}$. The time spent searching for each object was recorded, and the duration was evaluated as the degree of cognitive function.

Evaluation of $A \beta$ deposition in the brain

The mouse brains were soaked in $4 \%$ paraformaldehyde at $4{ }^{\circ} \mathrm{C}$ for $24 \mathrm{~h}$. After fixation in $4 \%$ paraformaldehyde, the brains were then embedded in paraffin and sectioned at $5 \mu \mathrm{m}$. The mandibular bone was soaked in $4 \%$ paraformaldehyde at $4{ }^{\circ} \mathrm{C}$ for $48 \mathrm{~h}$. The brain sections were immunostained using anti-A $\beta$ antibody $82 \mathrm{E} 1$ and visualized by the avidin-biotin-peroxidase complex procedure (Vectastain Elite $A B C$ kit, Vector Laboratories, Burlingame, Canada) using diaminobenzidine (ImmPact DAB, Vector Laboratories) as the chromogen. Then the sections were observed with a microscope (OLYMPUS, Tokyo, Japan). The number of immunopositive pixels in the hippocampus were counted, and the values were converted to the area as the amount of $A \beta$ deposition. ${ }^{39}$

Measurements of $A \beta$ oligomer, TNF- $\alpha$, and IL-1 $\beta$ in the brain Human oligomerized $A \beta$ was measured using an ELISA kit purchased from Wako Pure Chemical Industries, according to the manufacturer's instructions. Briefly, the right hemispheres from the brains of transgenic APP/J20 mice treated with or without $P$. gingivalis were collected and homogenized. Quantification of total protein was determined using a Micro BCA protein assay kit and was measured on an absorbance microplate reader (Molecular Devices, Sunnyval, CA). The homogenates were centrifuged at $100,000 \times g$ for $20 \mathrm{~min}$ at $4^{\circ} \mathrm{C}$. Levels of TNF- $\alpha$ and IL-1 $\beta$ in the supernatants were measured by ELISA (R\&D systems Inc., Minneapolis, MN) according to the manufacturer's instructions. Insoluble materials in the sediments were sonicated in PBS with $6 \mathrm{M}$ guanidine hydrochloride and were centrifuged at $100,000 \times g$ for $20 \mathrm{~min}$ at $4^{\circ} \mathrm{C}$. The supernatant was then diluted 1:10 before carrying out the sandwich ELISA, which measures insoluble $A \beta$ oligomer levels, but not amyloid monomers, as detailed in the manufacturer's protocol. The final $A \beta$ oligomer values were determined following normalization of total protein levels. ${ }^{49}$

\section{Detection of endotoxin in the brain}

The endotoxin in mouse serum and brain lysate was measured by a Limulus assay using an Endospecy ES-50M kit (Seikagaku Co., Tokyo, Japan). ${ }^{50}$

\section{Measurement of TNF- $\alpha$ and IL-1 $\beta$ in microglia cultures}

A 6-3 microglia cell clone culture kit (Cosmo Bio Co. Ltd., Tokyo, Japan) was used in this study. The microglial cell line $6-3\left(2 \times 10^{4}\right.$ cells $\left./ \mathrm{cm}^{2}\right)$ was seeded in 96-well culture plates and incubated for $24 \mathrm{~h}$. The cells were then stimulated with $10 \mu \mathrm{M} \mathrm{A \beta} 42$ for $6 \mathrm{~h}$ and further stimulated with $P$. gingivalis-derived LPS $(0.01,0.1,1.0 \mu \mathrm{g} / \mathrm{ml}$, LPS-PG from Invitrogen, San Diego, CA) for $24 \mathrm{~h}$. Levels of TNF- $\alpha$ and IL-1 $\beta$ in the media were measured using an ELISA kit (R\&D Systems) according to the manufacturer's instructions. ${ }^{51}$ 


\section{Measurement of $A \beta$ oligomer in murine neuron cultures}

Primary neuronal cultures were prepared from the cortices of embryonic day 17 C57BL/6 mouse embryos. ${ }^{52}$ Briefly, cortices were dissected and the meninges were freed. The cortical fragments were incubated with $0.25 \%$ trypsin and $20 \mathrm{\mu g} / \mathrm{ml}$ DNase I in phosphate-buffered saline at $37^{\circ} \mathrm{C}$ for 15 min, dissociated into single cells by pipetting, and then resuspended in serum-free Dulbecco's modified Eagle's medium/Ham's F-12 (Wako Pure Chemical Industries, Osaka, Japan) supplemented with N2 Supplement with Transferrin (Wako Pure Chemical Industries, Osaka, Japan) supplemented with N2 Supplement with Transferrin (Wako Pure Chemical Industries, Osaka, Japan). ${ }^{53}$ Primary neuronal cells were plated in polyethylene-imine-coated 12-well plates at a density of $1 \times 10^{6}$ cells per well. The neurons were stimulated with or without $0.1,1,10 \mu \mathrm{g} / \mathrm{ml}$ of $P$. gingivalis-derived LPS for $24 \mathrm{~h}$. Then levels of $A \beta 40$ and $A \beta 42$ in the media were measured by an ELISA (Wako Pure Chemical Industries).

\section{Statistics}

Statistical analyses were performed using an unpaired Student's $t$-test. Multiple comparisons were performed by one-way analysis of variance and the Bonferroni or Dunn method, with results presented as means \pm standard deviation. P-values less than 0.05 were considered statistically significant.

\section{Approval of experimental protocol}

All experimental protocols were approved by institutional guidelines of the Aichigakuin University and National Center for Geriatrics and Gerontology.

\section{Data availability}

The data that support the findings of this study are available from the corresponding author upon reasonable request.

\section{ACKNOWLEDGEMENTS}

This work was supported by The Research Funding for Longevity Sciences (26-21) from National Center for Geriatrics and Gerontology (NCGG), Japan. It is also supported by a Grant-in-Aid for Scientific Research (B) (26293438) (to K.M.) and a Grant-in-Aid for Young Scientists (B)(17K17362) (to N.I.) from the Ministry of Education, Culture, Sports, Science, and Technology, Japan.

\section{AUTHOR CONTRIBUTIONS}

K.M. and M.M. had the idea and initiated the study. N.I, U.I., H.T., Y.F.-K., M.H., A.M., T. F., M.A., M.M., and K.M. managed the study and collected the data. N.I, U.I., H.T., Y.F.K., M.H., M.M., and K.M. were responsible for and performed the assays. N.I., U.I., H.T., Y.F.-K., M.H., A.M., M.M., and K.M. performed the analyses and interpreted the data. N. I., U.I., M.M., and K.M. drafted the manuscript. All authors amended and commented on the final manuscript.

\section{ADDITIONAL INFORMATION}

Supplementary information accompanies the paper on the npj Aging and Mechanisms of Disease website (https://doi.org/10.1038/s41514-017-0015-x).

Competing interests: The authors declare no competing financial interests.

Publisher's note: Springer Nature remains neutral with regard to jurisdictional claims in published maps and institutional affiliations.

\section{REFERENCES}

1. Herrera, B. S. et al. Peripheral blood mononuclear phagocytes from patients with chronic periodontitis are primed for osteoclast formation. J. Periodontol. 85, e72-e81 (2014).

2. Taylor, G. W. et al. Severe periodontitis and risk for poor glycemic control in patients with non-insulin-dependent diabetes mellitus. J. Periodontol. 67, 1085-1093 (1996).

3. Huang, Y. F. et al. The impact of oral hygiene maintenance on the association between periodontitis and osteoporosis: a nationwide population-based cross sectional study. Medicine 95, e2348 (2016).

4. Tonetti, M. S. Periodontitis and risk for atherosclerosis: an update on intervention trials. J. Clin. Periodontol. 36(Suppl 1), 15-19 (2009).
5. Bochenek, G. et al. The large non-coding RNA ANRIL, which is associated with atherosclerosis, periodontitis and several forms of cancer, regulates ADIPOR1, VAMP3 and C11ORF10. Hum. Mol. Genet. 22, 4516-4527 (2013).

6. Renvert, S., Berglund, J., Persson, R. E. \& Persson, G. R. Osteoporosis and periodontitis in older subjects participating in the Swedish National Survey on Aging and Care (SNAC-Blekinge). Acta Odontol. Scand. 69, 201-207 (2011).

7. Katz, J., Marc, H., Porter, S. \& Ruskin, J. Inflammation, periodontitis, and coronary heart disease. Lancet 358, 1998 (2001).

8. Kelly, J. T., Avila-Ortiz, G., Allareddy, V., Johnson, G. K. \& Elangovan, S. The association between periodontitis and coronary heart disease: a quality assessment of systematic reviews. J. Am. Dent. Assoc. 144, 371-379 (2013).

9. Finucane, T. E. Periodontitis, edentulism, and dementia. J. Am. Geriatr. Soc. 61, 2060 (2013).

10. Noble, J. M. et al. Serum lgG antibody levels to periodontal microbiota are associated with incident Alzheimer disease. PLoS One 9, e114959 (2014).

11. Rai, B., Kaur, J. \& Anand, S. C. Possible relationship between periodontitis and dementia in a North Indian old age population: a pilot study. Gerodontology 29, e200-e205 (2012).

12. Singhrao, S. K. et al. Oral inflammation, tooth loss, risk factors, and association with progression of Alzheimer's disease. J. Alzheimer's Dis. 42, 723-737 (2014).

13. Wu, Z. \& Nakanishi, H. Connection between periodontitis and Alzheimer's disease: possible roles of microglia and leptomeningeal cells. J. Pharmacol. Sci. 126, 8-13 (2014).

14. Galasko, D. New approaches to diagnose and treat Alzheimer's disease: a glimpse of the future. Clin. Geriatr. Med. 17, 393-410 (2001).

15. Folstein, M. F. \& Whitehouse, P. J. Cognitive impairment of Alzheimer disease. Neurobehav. Toxicol. Teratol. 5, 631-634 (1983).

16. Selkoe, D. J. Defining molecular targets to prevent Alzheimer disease. Arch. Neurol. 62, 192-195 (2005).

17. Takeda, S., Sato, N. \& Morishita, R. Systemic inflammation, blood-brain barrier vulnerability and cognitive/non-cognitive symptoms in Alzheimer disease: relevance to pathogenesis and therapy. Front. Aging Neurosci. 6, 171 (2014).

18. Shankar, G. M. et al. Amyloid-beta protein dimers isolated directly from Alzheimer's brains impair synaptic plasticity and memory. Nat. Med. 14, 837-842 (2008).

19. McGeer, P. L. \& McGeer, E. G. The amyloid cascade-inflammatory hypothesis of Alzheimer disease: implications for therapy. Acta Neuropathol. 126, 479-497 (2013).

20. Miguel-Alvarez, M. et al. Non-steroidal anti-inflammatory drugs as a treatment for Alzheimer's disease: a systematic review and meta-analysis of treatment effect. Drugs Aging 32, 139-147 (2015).

21. Akiyama, H. et al. Inflammation and Alzheimer's disease. Neurobiol. Aging 21, 383-421 (2000).

22. Ridolfi, E., Barone, C., Scarpini, E. \& Galimberti, D. The role of the innate immune system in Alzheimer's disease and frontotemporal lobar degeneration: an eye on microglia. Clin. Dev. Immunol. 2013, 939786 (2013).

23. D'Aiuto, F. et al. Periodontitis and systemic inflammation: control of the local infection is associated with a reduction in serum inflammatory markers. J. Dent. Res. 83, 156-160 (2004).

24. Poole, S., Singhrao, S. K., Kesavalu, L., Curtis, M. A. \& Crean, S. Determining the presence of periodontopathic virulence factors in short-term postmortem Alzheimer's disease brain tissue. J. Alzheimer's Dis. 36, 665-677 (2013).

25. Shaftel, S. S. et al. Sustained hippocampal IL-1 beta overexpression mediates chronic neuroinflammation and ameliorates Alzheimer plaque pathology. J. Clin. Invest. 117, 1595-1604 (2007).

26. Dal Pra, I. et al. Emerging concepts of how beta-amyloid proteins and proinflammatory cytokines might collaborate to produce an 'Alzheimer brain' (Review). Mol. Med. Rep. 1, 173-178 (2008).

27. Clark, I. A. \& Vissel, B. Amyloid beta: one of three danger-associated molecules that are secondary inducers of the proinflammatory cytokines that mediate Alzheimer's disease. Br. J. Pharmacol. 172, 3714-3727 (2015).

28. Targonska-Stepniak, B. \& Majdan, M. Serum amyloid A as a marker of persistent inflammation and an indicator of cardiovascular and renal involvement in patients with rheumatoid arthritis. Mediat. Inflamm. 2014, 793628 (2014).

29. Lee, J. W. et al. Neuro-inflammation induced by lipopolysaccharide causes cognitive impairment through enhancement of beta-amyloid generation. J. Neuroinflamm. 5, 37 (2008).

30. Poole, S. et al. Active invasion of Porphyromonas gingivalis and infection-induced complement activation in ApoE-/- mice brains. J. Alzheimer's Dis. 43, 67-80 (2015).

31. Komatsu, T. et al. E-Selectin mediates Porphyromonas gingivalis adherence to human endothelial cells. Infect. Immun. 80, 2570-2576 (2012).

32. Chang, L. C. et al. Regulation of ICAM-1 expression in gingival fibroblasts infected with high-glucose-treated P. gingivalis. Cell. Microbiol. 15, 1722-1734 (2013).

33. Kato, Y. et al. TNF-alpha augmented Porphyromonas gingivalis invasion in human gingival epithelial cells through Rab5 and ICAM-1. BMC Microbiol. 14, 229 (2014). 
34. Takeda, S. et al. Increased blood-brain barrier vulnerability to systemic inflammation in an Alzheimer disease mouse model. Neurobiol. Aging 34, 2064-2070 (2013).

35. Veeraraghavalu, K., Zhang, C., Zhang, X., Tanzi, R. E. \& Sisodia, S. S. Age-dependent, non-cell-autonomous deposition of amyloid from synthesis of betaamyloid by cells other than excitatory neurons. J. Neurosci. 34, 3668-3673 (2014).

36. Chakrabarty, P. et al. IL-10 alters immunoproteostasis in APP mice, increasing plaque burden and worsening cognitive behavior. Neuron 85, 519-533 (2015).

37. Oue, $\mathrm{H}$. et al. Tooth loss might not alter molecular pathogenesis in an aged transgenic Alzheimer's disease model mouse. Gerodontology. https://doi.org/ 10.1111/ger.12153 (2014).

38. Okamoto, N. et al. Association between tooth loss and the development of mild memory impairment in the elderly: the Fujiwara-kyo study. J. Alzheimer's Dis. https://doi.org/10.3233/JAD-141665 (2014).

39. Oue, H. et al. Tooth loss induces memory impairment and neuronal cell loss in APP transgenic mice. Behav. Brain Res. 252, 318-325 (2013).

40. Okihara, $H$. et al. Liquid diet induces memory impairment accompanied by a decreased number of hippocampal neurons in mice. J. Neurosci. Res. 92, 1010-1017 (2014).

41. Fettelschoss, A., Zabel, F. \& Bachmann, M. F. Vaccination against Alzheimer disease: an update on future strategies. Hum. Vaccin. Immunother. 10, 847-851 (2014).

42. Bateman, R. J. et al. Clinical and biomarker changes in dominantly inherited Alzheimer's disease. N. Engl. J. Med. 367, 795-804 (2012)

43. Saito, S. \& Murase, K. Ex vivoimaging of mouse brain using micro-CT with nonionic iodinated contrast agent: a comparison with myelin staining. Br. J. Radiol. 85, e973-e978 (2012).

44. Lopez-Toledano, M. A. \& Shelanski, M. L. Increased neurogenesis in young transgenic mice overexpressing human $\operatorname{APP}(S w, I n d)$. J. Alzheimers Dis. 12, 229-240 (2007)

45. Wright, A. L. et al. Neuroinflammation and neuronal loss precede Abeta plaque deposition in the hAPP-J20 mouse model of Alzheimer's disease. PLoS One 8 e59586 (2013).

46. Zhang, W., Ju, J., Rigney, T. \& Tribble, G. Porphyromonas gingivalis infection increases osteoclastic bone resorption and osteoblastic bone formation in a periodontitis mouse model. BMC Oral Health 14, 89 (2014).
47. Nishikawa, T. et al. nvolvement of nitrosative stress in experimental periodontitis in diabetic rats. J. Cnin. Periodontol. 39, 342-349 (2012).

48. Mouri, A. et al. Thyrotoropin receptor knockout changes monoaminergic neuronal system and produces methylphenidate-sensitive emotional and cognitive dysfunction. Psychoneuroendocrinology 48, 147-161 (2014).

49. Parthsarathy, V. et al. A novel retro-inverso peptide inhibitor reduces amyloid deposition, oxidation and inflammation and stimulates neurogenesis in the APPswe/PS1DeltaE9 mouse model of Alzheimer's disease. PLoS One 8, e54769 (2013).

50. Kadowaki, T., Inagawa, H., Kohchi, C., Hirashima, M. \& Soma, G. Preparation of lipopolysaccharide derived from Pantoea agglomerans labeled with fluorescence as a tracer for kinetics analysis. Anticancer Res. 30, 3151-3157 (2010).

51. Park, S. Y. et al. Alpha-Iso-cubebenol inhibits inflammation-mediated neurotoxicity and amyloid beta 1-42 fibril-induced microglial activation. J. Pharm. Pharmacol. 66, 93-105 (2014).

52. Doi, Y. et al. Microglia activated with the toll-like receptor 9 ligand CpG attenuate oligomeric amyloid \{beta\} neurotoxicity in in vitro and in vivo models of Alzheimer's disease. Am. J. Pathol. 175, 2121-2132 (2009).

53. Mizuno, T. et al. Neuroprotective role of phosphodiesterase inhibitor ibudilast on neuronal cell death induced by activated microglia. Neuropharmacology 46 404-411 (2004).

(i) Open Access This article is licensed under a Creative Commons cc) Attribution 4.0 International License, which permits use, sharing, adaptation, distribution and reproduction in any medium or format, as long as you give appropriate credit to the original author(s) and the source, provide a link to the Creative Commons license, and indicate if changes were made. The images or other third party material in this article are included in the article's Creative Commons license, unless indicated otherwise in a credit line to the material. If material is not included in the article's Creative Commons license and your intended use is not permitted by statutory regulation or exceeds the permitted use, you will need to obtain permission directly from the copyright holder. To view a copy of this license, visit http://creativecommons. org/licenses/by/4.0/.

(c) The Author(s) 2017 